\title{
Research Highlights of the Indian Contributions to Geomagnetism and Aeronomy in the $21^{\text {st }}$ Century
}

\author{
A MANGLIK \\ CSIR-National Geophysical Research Institute, Uppal Road, Hyderabad 500 007, India
}

(Received on 16 May 2018; Accepted on 04 October 2018)

\begin{abstract}
Study of the Earth's magnetism is one of the oldest disciplines of geosciences whose history dates back to several centuries. The field has played a vital role in fostering formal international cooperation as back in time as more than two centuries. India has been a part of this endeavor and started geomagnetic observations almost at the same time as anywhere else in the world. IAGA, the International Association of Geomagnetism and Aeronomy, one of the eight Associations of the IUGG, is dedicated to the promotion of international research cooperation in the field of Geomagnetism and Aeronomy covering very diverse disciplines, from the magnetism of the Sun and other planetary bodies, solar winds, magnetosphere and upper Atmosphere, to the Earth's internal structure and processes. A significant amount of research work in these fields has been carried out by Indian researchers in the $21^{\text {st }}$ Century, a majority of which has been reported in various Indian National Reports to the IUGG. This article provides a glimpse of some of these studies carried out by Indian researchers in the last one decade in field of Geomagnetism and Aeronomy. It is not an exhaustive review of all the work done during this period but a window to the topics covered within the framework of IAGA.
\end{abstract}

Keywords: Geomagnetism; Aeronomy; IAGA; IUGG

\section{Introduction}

Study of the earth's magnetism is one of the oldest disciplines of geosciences whose history goes back to several centuries. According to the historical records the Chinese had discovered the existence of magnetism more than two millennium B.C. but the first detailed description of a magnetic compass in China dates back to 1088 A.D. (c.f. Lanza and Meloni, 2006). The first description of the use of a magnetic needle in European literature comes from 1190. Over the centuries, there were several developments to explore the magnetic properties of matter, the concepts of magnetic polarity, declination and inclination, and especially the use of magnetic needle for maritime navigation. However, the first comprehensive description of the geomagnetic field in modern world, De Magnete, was published by William Gilbert in 1600 . The $19^{\text {th }}$ century witnessed a quantum jump in the field of geomagnetism when Carl Friedrich Gauss published the theory of geomagnetism (1832-1840) and for the first time gave a procedure for the measurement of magnetic field intensity. Another major impetus in the study of geomagnetism came in 1919 when Larmor linked the origin of the earth's magnetic field to a self-sustaining dynamo mechanism operating within the earth. The field of geomagnetism has grown significantly in the past one century both on observational front using a network of ground observatories, airborne and satellite measurements, and theory development through largescale simulations of the internal and the external fields.

The field of geomagnetism has played a vital role in developing formal international cooperation as back in time as more than two centuries. Alexander von Humboldt organized widespread simultaneous magnetic observations in the first decade of the nineteenth century. Later, Carl Friedrich Gauss along with Wilhelm Eduard Weber and Alexander von Humboldt founded the Magnetic Union, which fostered the institution of magnetic observatories during 1836-1841 resulting in simultaneous observations at more than 50 observatories distributed

*Author for Correspondence: E-mail: ajay@ngri.res.in 
over five continents (Ismail-Zadeh, 2016). These were some major efforts on international cooperation that, along with development in other sub-disciplines of geosciences, led to the creation of the International Research Council, the predecessor of the International Council for Science (ICSU) in 1918 and the International Union of Geodesy and Geophysics (IUGG) in 1919. IAGA, the International Association of Geomagnetism and Aeronomy, is one of the eight Associations of the IUGG. It is one of the major Associations of the IUGG that deals with the understanding and knowledge from studies of the magnetic and electrical properties of the (i) Earth's core, mantle and crust, (ii) the middle and upper atmosphere, (iii) the ionosphere and the magnetosphere, and (iv) the Sun, the solar wind, the planets and interplanetary bodies through its six Divisions and several Working Groups.

Geomagnetic observations in India started almost at the same time as anywhere else in the world and have a history of more than two centuries. The first magnetic observatory was established at Madras (now Chennai) in 1792 where regular observations started from 1822 and continued till 1881. Another observatory was established at Shimla under the plan of the Göttingen Magnetic Union where magnetic observations were recorded at hourly intervals during 1841-1845 (Rastogi, 1986). The observatory at Trivandrum was constructed in 1837 but the actual observations started in 1841 and continued till 1870 with a brief hiatus between 1860 and 1863 (Basavaiah, 2012). Realizing the importance of this place as close to the magnetic equator, another observatory was setup at Augustia Malley about 22 $\mathrm{km}$ ENE of Trivandrum (Rastogi, 1986). Although the earliest observations were made at Madras, the beginning of the era of Indian geomagnetism is attributed to the establishment of the Colaba observatory at Bombay (now Mumbai) where magnetic measurements started in 1841 (Rastogi 1986; Basavaiah 2012). In 1904, another observatory was started at Alibag about $35 \mathrm{~km}$ SSE of Bombay. These two observatories together provide the longest series of magnetic data anywhere in the world (Rastogi, 1986).

In India, many Institutes pursue research activities related to the IAGA domain of Geomagnetism and Aeronomy. Among these, Indian
Institute of Geomagnetism (IIG), Navi Mumbai, is the nodal Institute for operating geomagnetic observatory network, acquiring data in the form of annual data bulletins as well as maintaining repository of the digital data generated by the National Geomagnetic Observatory Network. Sister Institutions, e.g. CSIRNational Geophysical Research Institute (CSIRNGRI), Hyderabad, Indian Institute of Astrophysics (IIA), Bengaluru, and Survey of India (SoI), Dehradun, co-ordinate and supplement the operation of geomagnetic observatories. In addition to the geomagnetic observatories, IIG along with its regional centers at Tirunavelli and Allahabad, and Space Physics Laboratory (SPL), Thiruvananthapuram, CSIR-National Physical Laboratory (CSIR-NPL) New Delhi, Guwahati University, Guwahati operate a network of Digital Ionosonde, Partial Reflection Radar, Meter Wind Radar, and Optical Radars across the country (Arora and Veenadhari, 2015). Physical Research Laboratory (PRL) operates a solar observatory at Udaipur. In Solid Earth Geophysics, many institutes, IITs and universities work in the field of electromagnetic geophysics, paleomagnetism, and earthquake precursory studies.

Since the inception of geomagnetism studies in India with the installation of geomagnetic observatory, enormous research work has been carried out in India covering different aspects, from space weather to the earth's interior. A lucid description of the Indian contribution to Geomagnetism and Aeronomy has been presented by Rastogi (1986). Bhardwaj et al. (2016) have reviewed the status of space weather research in India. The present paper is aimed at briefly listing the major contributions from India in the $21^{\text {st }}$ century in the realm of IAGA. However, it is not an exhaustive review of all the Indian contribution to Geomagnetism and Aeronomy during this period.

\section{Contributions in the $21^{\text {st }}$ Century}

A significant amount of research work in the field of Geomagnetism and Aeronomy has been carried out by Indian researchers in the $21^{\text {st }}$ Century, a majority of which has been reported in various Indian National Reports to the IUGG (Lakhina, 2003; Bhattacharyya, 2007, 2011; Arora and Veenadhari, 2015). Here, a brief account of the major studies during the past one decade is covered. The article is sub-divided into Sections following IAGA classification of Divisions. 


\section{Internal Magnetic Fields}

\section{Theory of Planetary Magnetic Fields}

Studies related to the 3-D dynamo simulations of planetary magnetic fields have been initiated in India. In one study, the effect of thermo-compositional convection on generation of planetary magnetic field through a dynamo mechanism was studied. For terrestrial planets having growing solid inner core, such as the Earth, the release of light density elements at the inner core boundary contributes to convection through compositional buoyancy force. The difference in the thermal and compositional diffusivities may lead to interesting double-diffusive effects. Manglik et al. (2010) studied this process of double-diffusive convection by solving two separate transport equations with different diffusivities in a double diffusive dynamo model for the planet Mercury. They have found significant changes in the resulting magnetic field in double-diffusive models. Breuer et al. (2010) studied the influence of thermal and compositional driving sources on double diffusive convection for a large Ekman number of $10^{-3}$ and moderate Rayleigh numbers. Sahoo and Sreenivasan (2017) studied the onset of convection in a rotating spherical shell subject to laterally varying heat flux at the outer boundary at low Ekman number where the natural length scale of convection is significantly smaller than the length scale imposed by the boundary heat flux pattern. Contrary to earlier studies at a higher Ekman number, they found a substantial reduction in the onset Rayleigh number $\left(\mathrm{R}_{\mathrm{ac}}\right)$ with increasing lateral variation. The decrease in $\mathrm{R}_{\mathrm{ac}}$ is shown to be closely correlated to the equatorial heat flux surplus in the steady, basic state solution. The results also showed a notable analogy between the role of a laterally varying boundary heat flux and the role of a laterally varying magnetic field in confining small-scale convection. Simultaneously, an experimental facility has been set up at Indian Institute of Science, Bengaluru to study dynamo process and experiments have been carried out to investigate the convection in a rapidly rotating tangent cylinder (TC), for Ekman numbers down to $E=3.36 \times 10^{-6}$ (Aujogue et al., 2017).

\section{Paleomagnetism}

Flow-by-flow paleomagnetic measurements of 37 lava flows in the $900 \mathrm{~m}$-thick, isolated lava pile around Mandla in the eastern Deccan Volcanic Province
(DVP) reveals multiple magnetic polarity events: implying C29n-C28r-C28n magnetostratigraphy. The Virtual Geomagnetic Pole (VGP) position determined for these lavas, when compared with the Deccan Super Pole, indicates concordance with the main Deccan volcanic province, thus assigning a shorter period of eruption close to the Cretaceous-Palaeogene boundary $(\mathrm{K} / \mathrm{PB})$ for the eastern and western Deccan Traps (Pathak et al., 2016). The Damodar valley within the Chhotanagpur Gneissic terrain at the northern-most margin of the Singhbhum craton, eastern India, is perhaps the only geological domain in the entire Indian shield which hosts the early Cretaceous Rajmahal as well as the late Cretaceous Deccan igneous activities. Intrusives from the Damodar valley distinguished two generations of the activities belonging to the Deccan Traps ( $\sim 65 \mathrm{Ma})$ and to the Rajamahal Traps (110-115 Ma) magmatism (Srivastava et al., 2014).

A refined paleomagnetic pole for the Upper Vindhyan sequence inferred that the Seychelles microcontinent formed the western margin of the Rodinia Supercontinent at 750-755 Ma. Neoproterozoic igneous rocks of Malani (NW India), Bhopal Inlier, the Seychelles and northern Madagascar probably constituted an Andean type arc, formed on the western margin of East Gondwanaland, above an east dipping subduction zone (Venkateshwarlu and Mallikarjuna Rao, 2013). Similarity of refined palaeomagnetic poles for the Eastern Dharwar craton kimberlites with the Eastern Dharwar and the Bundelkhand cratons support (i) a Mesoproterozoic closure age for the 'Purana' sedimentary basins and (ii) accretion of the northern and southern Indian blocks prior to $1.1 \mathrm{Ga}$ contrary to several earlier tectonic models which consider them to be distinct blocks at that time (Dash et al., 2013; Venkateshwaulu and Chalapathi Rao, 2013; Radhakrishna et al., 2013).

Precambrian paleomagnetic records from dyke swarms provide a unique source of information regarding the Archean geomagnetic field and more specifically the average field strength produced by the early dynamo. A study was carried on 16 paleomagnetic sites from the Dharwar giant dyke swarm in southern India which was emplaced between 2.365 and $2.368 \mathrm{Ga}$. Two sites retained a pristine magnetization that yielded suitable directions and paleointensity estimates. The results indicate a mean 
field intensity of $9.2 \pm 7 \mu \mathrm{T}$ yielding a VDM value of $1.3+1 \times 10^{22} \mathrm{Am}^{2}$. Integration of these estimates within the present paleointensity database emphasizes the existence of a rather long period with pronounced low intensity during a few hundreds of millions years ( 2.3-1.8 Ga) (Valet et al., 2014).

\section{Rock- and Environmental Magnetism}

A state-of-the-art Environmental Geomagnetism Laboratory was setup at IIG in 2004 to study the geomagnetic field beyond the instrumented and archaeological timeframe and paleo-climate changes through multi-proxies utilizing lake, river and marine sedimentary cores. Basavaiah and Khadkikar (2004) defined a new parameter, S-ratio (backfield IRM/ SIRM), and showed that this parameter is more sensitive to climatic changes as compared to the magnetic susceptibility. Using this parameter, a composite climatic map for the entire Indian subcontinent was prepared, which suggested prevalence of prolonged dry spells $\sim 3,500$-years back along the eastern ( Iskapalli) and western ( $\sim \mathrm{Nal}$ Sarovar) coasts of India.

Environmental magnetism studies were performed on a sediment core from Schirmacher Oasis in East Antarctica. It is found that the glacial periods characterized by high of coarse SSD titanomagnetite were recorded during 40.78, 36.08, 34.51, 29.03 and, 28.02-21.45 cal. ka B.P. Relatively warm periods are documented during 38.44-39.22 cal. ka B.P., 33.7329.81 cal. ka B.P. and 28.52 cal. ka B.P. The LGM has documented the highest concentration of magnetic minerals, indicating widespread glaciation in the Schirmacher Oasis. The Holocene period is characterized by alternating phases of relatively warm (12.55-9.88 cal. ka B.P. and 4.21- 2 cal. ka B.P.) and cold (9.21-4.21 cal. ka B.P. and from $\sim 2$ cal. ka B.P. onwards) events (Warrier et al., 2014). A review of the application of magnetic stratigraphy to the Quaternary sedimentary records from India is presented by Sangode (2014).

In the past decade considerable studies have been carried out on fabric analysis of deformed rocks using Anisotropy of Magnetic Susceptibility (AMS). One of the most important applications of this technique has been in the vorticity analysis and deciphering of superposed deformation in rocks that are devoid of visible foliations and lineations (Mamtani and Arora, 2005; Mamtani and Sengupta, 2010; Mamtani, 2014). Integration of AMS data with field, microstructural and SEM-Electron Backscatter Diffraction (EBSD) data have helped in understanding structural control on fluid flow/vein emplacement and gold mineralization as well as in kinematic studies of quartzites, quartz veins and granitoids (Mondal and Mamtani, 2013; Lahiri and Mamtani, 2016; Renjith et al., 2016; Bhatt et al., 2016; Goswami et al., 2018).

The application of mineral magnetic techniques as pollution proxy for road deposited sediments has also been explored by using various statistical approaches. Road deposited sediments are a complex mix of particulates and contaminants accumulated on pavements and road surfaces. They are derived from extensive range of urban and industrial sources and are an important pathway for urban pollution (Kanu et al., 2017).

\section{Aeronomic Phenomena}

\section{Equatorial Plasma Bubble}

A phenomenon unique to the low latitude ionosphere is that of the equatorial plasma bubble (EPB). This is so because presence of a horizontal geomagnetic field at the dip equator makes the plasma on the bottomside of the equatorial ionospheric $\mathrm{F}$ region unstable to the growth of the Rayleigh-Taylor (R-T) instability in the post-sunset hours, giving rise to the EPB. Growth of EPBs involves the interchange of entire magnetic flux tubes. Hence they are aligned with the geomagnetic field lines so that irregularities at different altitudes over the dip equator map down along the geomagnetic field lines to ionospheric $\mathrm{F}$ region peaks at different latitudes, and thus may extend up to 15$20^{\circ}$ in latitude on either side of the dip equator for several hours after sunset. Importance of EPBs stems from the fact that the intermediate scale length $(\sim 100 \mathrm{~m}-\mathrm{few} \mathrm{km})$ irregularities in them scatter VHF and higher frequency trans-ionospheric radio waves, producing fluctuations or scintillations in their amplitude and phase, and thus have the potential to degrade the performance of satellite-based communication and navigation systems such as GNSS (Global Navigation Satellite Systems). Given the day-to-day variability of the ionosphere due to forcing from the atmosphere below and magnetosphere above it, there is a great deal of interest globally in prediction of the occurrence, strength, and other characteristics of EPBs, which 
are an important component of space weather in the low latitude ionosphere.

A large amount of work has been carried out in India as well as abroad, to study the effect of geomagnetic storms on the occurrence of EPBs and scintillation producing irregularities, because it is known that the equatorial ionospheric zonal electric field gets altered due to geomagnetic activity. One of the drawbacks of these studies was that the age of the $\mathrm{EPB}$, detected using radar, ionosonde, and scintillation observations, was not known. After the initial stage of their development, EPBs tend to drift eastward with the ambient plasma throughout the night. Hence, they could have been generated several hours earlier at a location to the west of the observer and then drifted overhead. Using scintillation observations and modeling Bhattacharyya et al. (2001) showed that in the initial stage of EPB development, the perturbation electric field associated with the R-T instability gave rise to fluctuations in the drift speed of the irregularities, which could be used to differentiate between nascent and fossilized EPBs. This enabled the proper identification of EPBs which were actually caused by geomagnetic activity (Bhattacharyya et al., 2002; Kakad et al., 2007).

The EPB is a night-time phenomenon, because during daytime geomagnetic field-aligned currents associated with EPBs can flow through a highly conducting E region to stop the growth of the instability. Just after sunset, the E-region electrical conductivity decreases but does not become zero. A transmission line analogy for the development of $\mathrm{EPBs}$, formulated to provide an explanation for satellite observations of magnetic field fluctuations associated with EPBs (Bhattacharyya and Burke, 2000), was extended into the non-linear regime to estimate the time taken by post-sunset E-region conductivity to discharge an EPB and hence its role in preventing chaotic evolution of EPBs to produce small-scale structure (Bhattacharyya, 2004).

Nearly all the remote sensing studies of EPB irregularities using radar, ionosonde, or scintillation observations, have tried to identify the basic conditions for the growth of the R-T instability by focusing on the various ambient parameters that appear in expressions for the linear growth rate of the R-T instability. However, for prediction of scintillations and development of structure in EPBs in the non-linear phase of their evolution is of critical importance. Towards this end, simultaneous observations of EPB irregularities using radar, and scintillation data on VHF (251 MHz), and GPS L-band radio signals were used as EPB irregularities of different scale sizes contribute to each of these observations (Sripathi et al., 2008). The GPS data were obtained under GAGAN (GPS Aided Geo-Augmented Navigation) project of ISRO and Airport Authority of India.

Spatial scales in the ground scintillation pattern of intensity variations produced by scattering of the incident radio waves by the EPB irregularities are converted into temporal scales in the scintillation data recorded by a ground receiver due to movement of the ground scintillation pattern across the receiver as the irregularities drift across the signal path. However, spatial scales in the ground pattern are directly related to the spatial spectrum of the irregularities only when the scattering is weak. Therefore, spectral studies of scintillation data may be used to directly study a powerlaw type of spatial spectrum of intermediate-scale EPB irregularities only when the scintillations are weak (Kakadet al., , 2012). Since most of the scintillation data does not fall into the weak category, a method was developed to estimate the dominant spatial scale (coherence scale) in the ground scintillation pattern using scintillation data of all strengths, which automatically adjusted for the irregularity drift variation (Bhattacharyya et al., 2003). This paved the way to study the temporal evolution of the irregularity spectrum near the equatorial F region peak, which is important for predicting scintillations recorded in the equatorial region (Bhattacharyya et al., 2014). Further, it was shown that the less dense top side of the equatorial $\mathrm{F}$ region was more structured than the equatorial $\mathrm{F}$ region peak, leading to much stronger scintillations on GNSS signals recorded around $15^{\circ}$ away from the dip equator (Bhattacharyya et al., 2017). This technique has also been used to study the structuring of EPBs produced by a magnetic storm (Kakad et al., 2016, 2017).

\section{Space Weather and Geomagnetic Storms}

A case of the westward disturbance dynamo (DD) electric field, influencing the daytime equatorial and low-latitude ionosphere, during a geomagnetic storm that occurred on 28-29 June 2013 (minimum 
Dst $\sim-130 \mathrm{nT}$ ) was studied. The GPS total electron content (TEC) observations from a network of stations in the Indian equatorial, low and middle latitude regions along with the radio beacon TEC, ionosonde, and magnetic field observations were used to study the storm time behavior of the ionosphere. The results reveal that there was hardly any change in the TEC over Shimla, Delhi and Trivandrum from the quietday mean behavior on 28 June 2013. The TEC over Bhopal (anomaly crest region) showed only a marginal increase (close to the standard deviation) in the afternoon hours. However, on 29 June 2013, the TEC over the stations Shimla, Delhi and Bhopal remained substantially low from morning till evening. This negative ionospheric storm effect seen over the low and middle latitudes is basically due to the presence of a westward Disturbance Dynamo Electric Field (DDEF) (Thampi et al., 2016).

The 2D (lat. $x$ long.) TEC maps have been generated by using the ionospheric correction data transmitted by the Indian Satellite Based Augmentation System (SBAS)-GAGAN. The advantage of this unique technique is the fact that by using a single SBAS-enabled receiver, the information over the entire region served by SBAS can be obtained irrespective of the location of the receiver. These 2D maps have been employed, for the first time, to investigate the effect of the most talked about space weather event of the current solar cycle, i.e., the St. Patrick's Day geomagnetic storm that triggered on 17 March 2015, on the equatorial and low-latitude region of the Indian longitudes. These 2D TEC maps for 16 March (Quiet day) and 17 March 2015 (Storm day), having a large latitudinal $\left(5^{\circ} \mathrm{S}-45^{\circ} \mathrm{N}\right)$ and longitudinal $\left(55^{\circ}-110^{\circ} \mathrm{E}\right)$ coverage, show the complete reversal in the longitudinal structure/pattern of EIA during the recovery phase of the storm as compared to the quiet day. It was observed that even a separation of few degrees in longitude $\left(\sim 15^{\circ}\right)$ could experience significantly different forcing (Yadav et al., 2016).

The impact of the geomagnetic storm event of 18-21 February 2014 (Dst $\sim 130 \mathrm{nT}$ ) on latitudinal changes in the disturbance electric fields and composition was studied. The GPS TEC data from the Indian Antarctic station, Bharati, the northern mid-latitude station Hanle, northern low-latitude station lying in the vicinity of the anomaly crest, Ahmedabad, and the geomagnetic equatorial station,
Trivandrum, were used for this purpose. The impact of the storm on the southern hemisphere high-latitude station was a drastic reduction in the TEC (negative ionospheric storm) The large decrease in TEC observed over Bharati could primarily be due to the composition changes related to the upwelling of the air rich in molecular species from the lower altitudes. The enhanced plasma densities seen over the midlatitude location, Hanle on 19 February were a consequence of this. On 19 February, there was an enhancement in TEC over Trivandrum, equatorial station and Ahmedabad, a low latitude station with a time delay (Shreedevi et al., 2016).

The first direct observational evidence for the possible role of meteoric activity in the generation of the equatorial Counter Electrojets (CEJ), an enigmatic daytime electrodynamical process over the geomagnetic quatorial upper atmosphere was presented using the data from Proton Precession Magnetometer and Meteor Wind Radar over a geomagnetic dip equatorial station, Trivandrum. The results revealed that the occurrence of the afternoon CEJ events during a month is directly proportional to the average monthly meteor counts over this location. The study proposed that the presence of meteoric ions reduces the strength of the upward polarization field thus paving way for easy reversal of field (Vineeth et al., 2016).

In the equatorial electrojet (EEJ) region, significant long wavelength (longitudinal range greater than $45^{\circ}$ ) day-to-day variations in the CEJ have been extensively reported but their short-wavelength $(\sim 1000 \mathrm{~km})$ variability is not well studied. In a recent study, Chandrasekhar et al. (2017) used geomagnetic data from two ground observatories, one at the southern tip of the Indian mainland (VEN) and the other from the Andaman - Nikobar islands (CBY), about $15^{\circ}$ apart to study the short-wavelength variations, if any. They demonstrated occurrence of local variability in the CEJ and suggested that the ionospheric electrodynamics and associated atmospheric-ionospheric effects could vary considerably between the sites separated at $15^{\circ}$ longitude both during quiet and disturbed periods. Archana et al. (2018) extended the work to three equatorial and low-latitude pairedstations/sites at $5^{\circ}$, $15^{\circ}$ and $20^{\circ}$ longitudinal separation in the Indian sector; (i) Minicoy and Alibag, (ii) Vencode and Hyderabad, 
and (iii) Campbell Bay and Nabagram and have shown that EEJ amplitudes increase from west to east whereas CEJ amplitudes increase from east to west.

The unique chain of Indian and Russian geomagnetic observatories, confined to a narrow longitude belt, was used to establish the solar quietday $(\mathrm{Sq})$ ionospheric current system. Conspicuous disappearance of Sq vortex during winter symbolized failure of ionosphere dynamo (Campbell et al., 1993). In recent years, this network in conjunction with partial reflection radar and measurement of mesospheric winds has shown dominance of inter-hemispheric currents and it has been used for proposing generating mechanism of counter electrojet within the tidal framework as well as strong auroral-equatorial electrojet coupling (Doumouya et al., 2003; Arora and Bhardwaj 2003; Vichare and Rajaram 2011; Vichare et al., 2012).

\section{Other Studies}

Extensive studies using multi-platform instruments have been carried out to study the impact of the solar eclipse of 10 January 2010 on middle and upper atmosphere over the Indian geomagnetic equatorial belt. The significant results of the study are (i) a large drop in the ambient electric field, by up to $65 \%$, during the eclipse bringing to the fore the long lasting paradox of conductivity enhancement during eclipse, (ii) reduction in the Total Electron Content not just at the magnetic equator but, more markedly, in the Equatorial Ionization Anomaly (EIA) zone, a further $10^{\circ}$ to the north, and (iii) reversal in the zonal winds to eastward direction in the entire altitude range above $100 \mathrm{~km}$ (Choudhary et al., 2011; Anil Kumar et al., 2013).

A comprehensive analysis of nocturnal thermospheric meridional wind pattern encompassing two solar cycles was carried out using the night time F-layer base height information from ionosondes located at two equatorial stations and Sriharikota. Significant difference is seen in winds between High Solar Activity (HSA) and Low Solar Activity (LSA) epochs, with less equator-ward winds during pre-midnight hours for HSA years. Mean wind response to Solar Flux Unit (SFU) is established quantitatively for all seasons for pre-midnight hours (Madhav Haridas et al., 2016).

A high-altitude balloon experiment (BEENS,
Balloon Experiment on the Electrodynamics of Near Space) was successfully conducted on a 110,000 cu. $m$ balloon platform from the TIFR's National Balloon Facility at Hyderabad on 14 December 2013 to probe stratospheric electric fields from low latitudes. The instrument packagefor the experiment comprised of four deployable booms for measurements of horizontal electric fields and one inclined boom for vertical electric field measurements, all equipped with conductingspheres at the tip. Float duration of about 4 hours at a ceiling altitude of $35 \mathrm{~km}$ could be achieved during this launch. A noticeable feature of the observations has been the detection of horizontal electric fields of $\sim 5 \mathrm{mVm}^{-1}$ at thestratospheric altitudes of $\sim 35 \mathrm{~km}$ (Gurubaran et al., 2017).

\section{Magnetospheric Phenomena, Solar Wind and Interplanetary Field}

Bhardwaj et al. (2016) present a detailed review of the work done at various institutions/universities in India in the last four decades which led to significant progress in the understanding the terrestrial magnetosphere-ionosphere-thermosphere domains as a coupled system and its response to the solar and interplanetary variability caused by varying space weather. The review also describes the ground observatories as well as space missions being pursued by Indian researchers.

\section{Geomagnetic Observatories, Surveys and Analyses}

\section{Observatory Network}

Indian Institute of Geomagnetism (IIG), Navi Mumbai, is the nodal Institute for operating geomagnetic observatory network (Fig. 1), acquiring data in the form of annual data bulletins as well as maintaining repository of the digital data generated by the National Geomagnetic Observatory Network. It maintains a network of 12 observatories, two of which are in the NE India (Shillong and Silchar) and one in the Andamans (Port Blair). The Alibag and Jaipur observatories maintained by IIG are a part of the International Real time Magnetic Observatory Network (INTERMAGNET). The Alibag observatory together with its predecessor Colaba Observatory, established in 1841, provide more than 175 years of geomagnetic time series data. The Institute also maintains a World Data Center for 


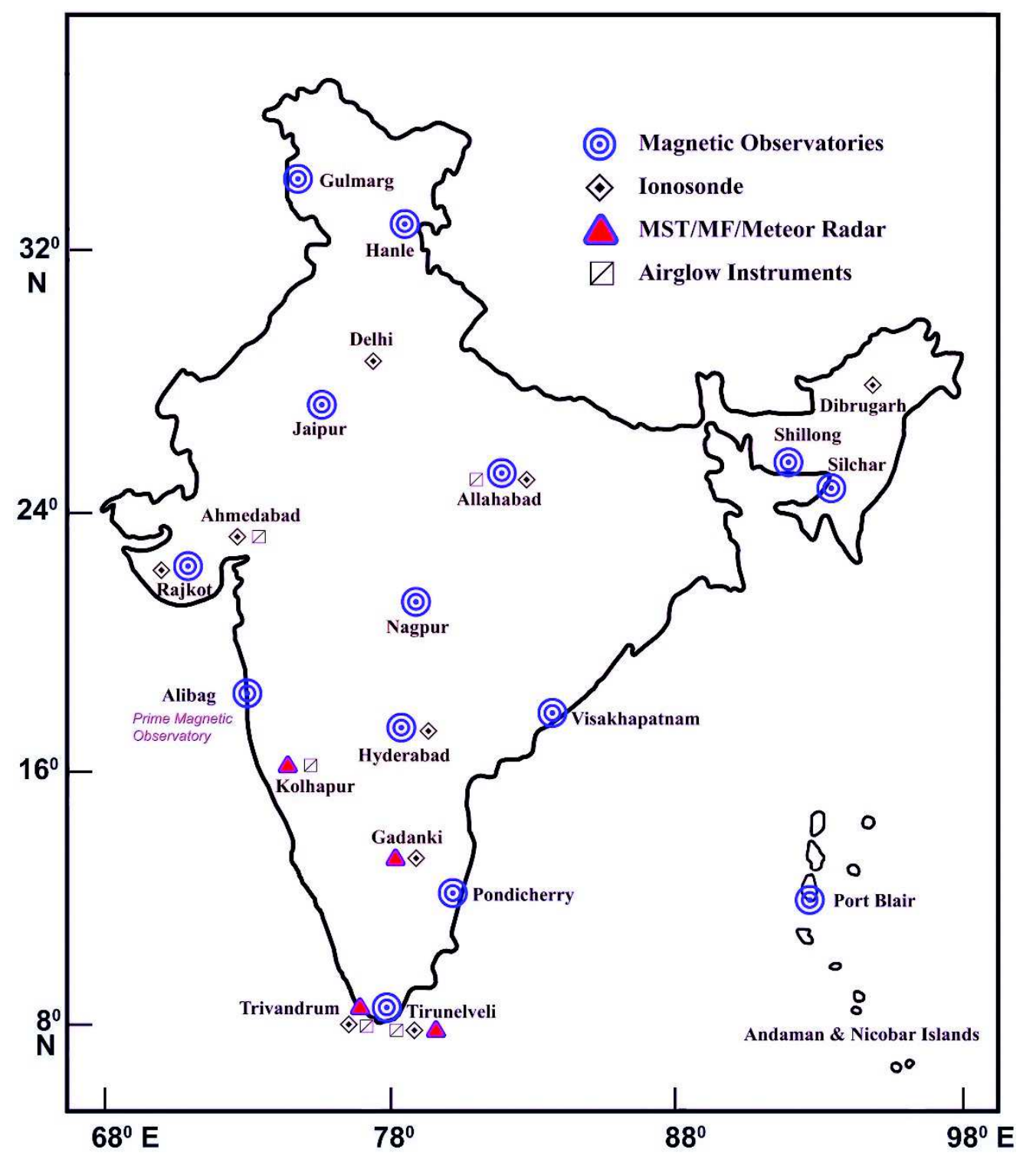

Fig. 1: Geomagnetic and Aeronomy observational network in India (after Arora and Veenadhari (2015))

Geomagnetism, WDC-Mumbai. In addition to these observatories, there are some more that are maintained by CSIR-National Geophysical Research Institute (CSIR-NGRI), Indian Institute of Astrophysics (IIA), and Survey of India (SoI).

The geomagnetic observatory of CSIR-NGRI at Hyderabad (HYB) was established in 1964 and has an uninterrupted baseline over the last 54 years. With renewed efforts and under collaboration with Adolf-Schmidt Observatory of GeoForschungs Zentrum (GFZ), Potsdam at Niemegk, HYB became an INTERMAGNET observatory in 2009 and the beginning of a new era for this observatory started in
2010 with complete digital data acquisition and processing to produce minute mean data. The raw data are transmitted with a few hours latency while the definitive data are submitted every year. Since 2016, storms and other events are reported to the Ebre Observatory, Spain and reporting of quasidefinitive data was started in 2012.

Geo-electric and pulsation observatories were established in Choutuppal in 1967 and Ettaiyapuram in 1970. Subsequently, Ettaiyapuram was closed down in 2002 and recording in Choutuppal was suspended in 1993. In 2012, work was initiated to re-establish the Choutuppal Observatory, which was completed 
in early 2014 with a complete digital acquisition and near real time transmission system. The efforts are ongoing to make it into an Observatory reporting one second data of INTERMAGNET standards. This kind of data will open up new avenues of research of the subtler signatures of the geomagnetic field.

During 2011 and over the next few years a network of Equatorial variometer sites has been setup in the Andaman-Nicobar and Lakshadweep Islands as well as at Kanyakumari, yielding minute data of vector variations. This data acquisition has been continued till present and has been the source of some important findings and publications on the variability of the Equatorial ionosphere. 2010-11 also saw the establishment of a new Observatory in Gan, Maldives, under a tripartite cooperation among Eidgenössische Technische Hochschule (ETH), Zürich, Maldives Meteorological Service (MMS), Maldives and CSIRNGRI, India. GAN is now an INTERMAGNET observatory.

In October 2014, an IAGA Observatory Workshop with 93 observers from 33 different countries was organized at CSIR-NGRI, Hyderabad. This was followed by the two-day long INTERMAGNET meeting. An ICSU project MAGNIO was awarded during 2014-15, which was intended to encourage regional cooperation among the northern Indian Ocean countries to share magnetic field data and work collaboratively on developing regional models. A start has been made in this direction and plans of a larger project to take it forward are in the offing.

Under an ongoing Indo-Russia collaboration, efforts are on to implement sophisticated processing techniques to handle such volumes and quality of data, leading to near real time reporting of major and minor events. Since the basic idea of one second data is to establish compatibility with the data derived from satellites, aspects of research involving ground and satellite (SWARM) data have also been started, providing interesting insights into the role of the equatorial atmosphere in modulating signatures of pulsations.

\section{Multi-parametric Geophysical Observatories and Earthquake Precursory Studies}

Multi-parametric Geophysical Observatories
(MPGOs) are being operated by Wadia Institute of Himalayan Geology (WIHG) in the Himalaya, Institute of Seismological Research (ISR) in the Kachchh intraplate seismic zone, and Indian Institute of Geomagnetism (IIG) in the Andamans.

\section{MPGO in the NW Himalaya}

WIHG established India's first MPGO at Ghuttu, Uttarakhand, immediate south of the Main Central Thrust (MCT), a major tectonic boundary in the Himalaya, to study earthquake precursor signals in the Himalaya in an integrated manned (Arora et al., 2012). It is located in a narrow belt of high seismicity where the colliding Indian - Asian plates are locked and it is expected that strains are accumulating for future great earthquakes. The observatory became operational in April 2007 and is equipped with a superconducting gravimeter, Overhauser and fluxgate magnetometers, ULF band search coil magnetometer, GPS, radon and water-level recorders. Supplemented by a dense network of broadband seismometers, the MPGO is designed to record precursory signals resulting from stress-induced changes in density, magnetization, resistivity, seismic wave velocity, fracture propagation, crustal deformation, electromagnetic and radon gas emission as well as fluctuations in hydrological parameters.

The data from the MPGO are analyzed to identify potential earthquake precursor signals. A sudden drop in the geomagnetic field intensity, lasting from several days before to a week after the earthquake, was observed for the Kharsali earthquake of 22 July 2007 ( $\left.M_{L} 4.9\right)$ (Arora et al., 2012). Similarly, the variability in the fractal dimension was studied for the data of 2010 and correlated with the earthquakes of $\mathrm{Me}>3.5$ within a zone of radius $150 \mathrm{~km}$ from the MPGO. It was found that the fractal dimension increased during the first half of the year when there was seismic activity whereas it had a steady behavior during the second half when there were no earthquakes. Similar study was carried out for the 20 June 2011 earthquake (Rawat, 2014).

\section{MPGOs in the Kachchh Region}

The Kachchh rift in Gujarat is one of the most seismically active intraplate regions in the world and lies in seismic zone V (BIS, 2002). Two large earthquakes, namely the 1819 Allahbund (Mw 7.9) 
and the 2001 Bhuj (Mw 7.7), occurred in this region. In order to pursue the science of medium- and shortterm precursors for earthquakes, ISR established three MPGOs, in March 2009, at Vamka, Badargadh and Desalpar, in the vicinity of the Wagad Fault area, Kachchh. These sites are east and northeast of the aftershock zone of 2001 Bhuj earthquake. A total of 11 types of precursory parameters are continuously monitored with Broadband Seismograph, Strong Motion Accelerograph, GPS, Magnetometers, Ground water leveler, Superconducting Gravimeter and Radon detectors. The Magnetometer setup comprises the Digital Fluxgate, Overhauser, D/I and ULF Magnetometers. ISR reports magnetic observations during magnetic storms, magnetic pulsations and local earthquakes. A number of studies have been carried out by ISR utilizing the data from these MPGOs, some of these are listed below.

\section{Earthquake Precursors}

Short-term earthquake prediction is considered to be one of the most important areas of research. The electromagnetic precursors are in the forefront among all precursors and tremendous progress has been achieved in the field of seismo-electromagnetics during the last two decades. ISR made an attempt to study the pre-seismic ULF emissions in the frequency band $0.001-0.5 \mathrm{~Hz}$ recorded by Digital Fluxgate Magnetometers and ULF Magnetometers at Desalpar, Badargadh and Vamka for 18 local earthquakes (M>3.7) during 2011-2017 including one earthquake of M5.0 on 20th June 2012. The magnetic data of mid-nights (i.e., 18-21 UT) were considered to reduce the manmade and atmospheric perturbations and analyzed with reference to local seismicity, geomagnetic storms and lightning events. In order to discriminate seismo-electromagnetic signatures from global geomagnetic effects, polarization analysis and principal component analysis were applied to the magnetic data. Moreover, fractal dimension analysis was also applied to understand the dynamics of earthquake processes. The results showed that the maximum variability in polarization ratio appeared during some of the local earthquakes, particularly prior to the moderate earthquake on 20th June 2012 (M 5.0). It is also observed that there is a marginal increase in the observed fractal dimensions few days before this earthquake. Similarly, the geomagnetic variations during eighteen small magnitude earthquakes (3.8-4.5) during 2011-17 reveal small anomalies before six earthquakes (30/03/2013, M4.4; 29th July 2013, M 4.5; 29th Sept 2014, M 3.8; 05/09/ 2015, M4.2; 07/12/2016, M 4.2; 23/08/2017, M 4.1). However, for small magnitude earthquakes, the preseismic signatures are observed in a few cases but are not seen in many cases and no uniform pattern is discernible.

\section{Magnetic Storms}

Magnetic data of three severe magnetic storms (18Mar2015; 23June2015 and 07Mar2016) were analyzed during the storm periods to investigate the characteristic of the local magnetic field components $\mathrm{dH}, \mathrm{dD}$ and $\mathrm{dZ}$ during the events. All three phases, i.e., initial, main and recovery are clearly visible in the H-Comp during these three storms. The most intense magnetic storm was observed on 21June 2015 with a Dst value of -205 and $K_{P}$ value of 9. During this storm, the sudden commencement (SC) in the form of sharp increase of the H-component occurred during the initial phase at 16:45 UT. Subsequently, the main phase occurred when the H-component decreased for long time duration. Finally, the recovery phase lasted for 8 days after the storm, until 29 June 2015. The solar wind Pressure, Density and IMF Bz are found to be more influencing parameters during the storm since they have a coherence $>0.6$. The correlation of solar wind velocity with total magnetic field is found to be 0.79 during the June 2015 storm.

\section{Schumann Resonances}

Schumann resonances (SchR) are the electromagnetic eigen-modes in the almost concentric spherical cavity formed by the Earth's surface and the lower ionosphere layers (at an altitude of approx. 50-60 km). These are obtained from ULF/ELF magnetic field emissions recorded by a set of 3-component search coil magnetometers (LEMI-30). The corresponding eigen-frequencies lie in the ELF range (the first one about $7.8 \mathrm{~Hz}$, then approx. 14, 20, $26 \mathrm{~Hz}$ and higher). Spectrograms of the Induction Coil Magnetometer data and their diurnal behavior for winter, summer seasons are studied. The clear appearance of first three bands of Schumann resonance has been observed over the two magnetically disturbed days. The effect of summer high solar glint is clearly seen on 07th Mar 2016. During the afternoon period, the 
resonance band has depleted with the high temperature. The same phenomenon has not been observed during the winter magnetic storm regime (1st February 2016).

\section{MPGO in the Andamans}

A new MPGO has been setup at Shoal Bay-8 in South Andaman by IIG. It started functioning from March, 2015.The MPGO hosts a variety of sophisticated instruments to monitor both long and short term excursions in the Earth's magnetic field at varied frequencies using Overhauser, Induction coil and Fluxgate magnetometers. It also houses Very Broad Band Seismometer, Ground Accelerometer and GPS to record both vertical and horizontal components of the seismic disturbances. In addition, various meteorological parameters are also being recorded.

\section{Electromagnetic Induction in the Earth and Planetary Bodies}

Electromagnetic (EM) induction techniques, e.g. magnetotellurics, have been extensively used by Indian researchers to delineate the crustal and lithospheric structureof various segments of the Indian peninsular shield as well as the plate boundary regions. Similarly, there is an increasing use of Transient EM techniques to map the near-surface region for mineral and groundwater, and geotechnical investigations. Some of the results are briefly mentioned below.

\section{Crustal Studies}

In the past 15 years, several MT profiles were covered across different segments of the Himalaya. These have provided new information about the crustal structure of the Himalayan collision belt. Long-period magnetotelluric MT data were collectedat 15 stations on a $250 \mathrm{~km}$ long profile in the northwest Indian Himalaya (Leh segment) to study the structure of this continent-continentcollision zone. The results revealed the presence of a broad low resistivity zone in the mid-crust beneath the ITSZ and Ladakh which was attributed to the presence of a few percent partial melt. The northern end of the profile showed a decrease in the deep resistivity of the lithosphere, similar to observations further east on the Tibetan Plateau (Arora et al., 2007).

Another profile was covered from Roorkee to Gangotri in the Uttarakhand Himalaya where MT data were acquired at 37 sites. The obtained 2D geoelectrical structure of the crust brings out, among many other features, a prominent low resistivity $(<10$ Ohm.m) feature in the MCT zone extending to the depth of $30 \mathrm{~km}$ indicating the presence of a ramp structure. Hypocenters of many earthquakes are concentrated along the boundary of this low resistivity zone and relatively high resistivity blocks around it. The model supports flat-ramp-flat geometry of the Main Himalayan Thrust (Miglani et al., 2014). A third, $250 \mathrm{~km}$ long, MT profile in the NW Himalaya was covered between Bijnaur in the Indo-Gangetic Plains and Mallari at the Southern Tibet Detachment (STD) zone. Geoelectrical resistivity cross-section derived from MT/LMT and vertical magnetic transfer function reveals a prominent low-angle north-east dipping intracrustal high conducting layer with change in depth from the Lesser Himalaya to the Higher Himalaya. This transition is interpreted as a Ramp in the Main Himalayan Thrust (MHT) that also coincides with the concentration of seismicity (Rawat et al., 2014).

In the Sikkim Himalaya where, as against the thrust dominated earthquakes, strike slip becomes the dominating earthquake mechanism, MT study along a $200-\mathrm{km}$-long profile suggested that the Main Himalayan Thrust forms the base of several resistive blocks within the wedge and that a ramp structure is present south of the Main Central Thrust Zone (MCTZ). Another significant result is that the crust and mantle lithosphere beneath the MCTZ and the Higher Himalayan Crystallines (HHC) seem to be compositionally/geologically different from the lithosphere south of the MCTZ. A steep crustal-scale fault with the Moho offset of $14 \mathrm{~km}$ is inferred to be separating these two blocks. The deep crustal seismicity could be related to this fault whereas shallow seismicity can be linked to the deformation within the wedge (Pavan Kumar et al., 2014).

In the central Ganga Basin, MT study was carried out along a $285 \mathrm{~km}$ long profile between Hamirpur and Rupadia (Nepal border) across the basin to understand its basement structure and sediment thickness. The thickness of sediments gradually increases to about 500-600 $\mathrm{m}$ at Kanpur, and to about $1.2 \mathrm{~km}$ at Lucknow, and the basement depth increases to more than $2.5 \mathrm{~km}$ within a profile distance of $20 \mathrm{~km}$, perhaps due to the presence of Lucknow fault. The sedimentary sequence at the 
northern end of the profile around Bahraich is more than $9 \mathrm{~km}$ thick. Integration of the resistivity model with published seismic velocity structure and borehole lithology revealed that the top $4 \mathrm{~km}$ succession is constituted of highly conductive Oligocene and younger rocks of the Matera Formation and the Siwaliks, and recent sediments. Whereas, the underlying $>5 \mathrm{~km}$ section is composed of sedimentary rocks of the Bahraich Group overlying the Archean basement (Manglik et al., 2015).

Synthesis of continuing MT surveys in the Deccan Volcanic Province (DVP) indicates that the thickness of the traps in DVP decreases from about $1.8 \mathrm{~km}$ in the west to a few hundred meters (approx. $400 \mathrm{~m}$ ) towards the east. The traps also exhibit considerable variation in resistivity, with higher resistivities (approx. 150-200 ohm-m) in the western half and lower resistivities (approx. 50-100 ohm-m) in the eastern half of DVP. Two significant fissure/ fracture zones have been detected in DVP, which might have acted as conduits for the outpouring of Deccan lavas in addition to the primary structures along the west coast and the Narmada-Son lineament (NSL) zones.

A 3D modeling of large-scale broad-band MT data covering the western segment of Narmada-Son lineament zone in Central India brought out several major crustal conductors with different geometries at different depth levels in the crustal column. The conductive features, correlating with gravity high anomalies and high seismic velocity zones were interpreted as mafic-ultramafic bodies derived from mantle and inferred to be resulted from the intrusive component of the Large Igneous Province (LIP) of the Deccan volcanic episode triggered by the passage of the Indian continent over the Reunion hot spot during the Late Cretaceous (Patro and Sarma, 2016).

Several deep EM imaging studies were carried out in the Indian shield region to elucidate the tectonics and geological history of the various critical geological segments. The evolutionary history and ambiguity in the suture location between the southern and northern blocks of the Indian peninsular shield were studied using magnetotelluric data acquired across the eastern segment of the Central Indian Tectonic Zone (CITZ). The study revealed deep crustal and upper mantle conductive anomalies associated to Tan Shear and suggested a suture status to the Tan Shear. Similar lithosphere scale imaging across western Dharwar craton and Coorg blocks in south India revealed the suture between the two blocks and indicated the individuality of the two Archean terrains. Broadband magnetotelluric investigations were carried out in the NE part of Cuddapah basin to image the conductivity structure of the Palnad sub basin and Nallamalai fold belt. The study suggested E-W compression along the eastern margin during the NeoarchaeanNeoproterozoic ( $2700 \mathrm{Ma}-970 \mathrm{Ma})$ tectonic convergence between India and east Antarctica (Naganjaneyulu and Santosh, 2012; Abdul Azeez et al., 2015, 2017).

The lithospheric electrical resistivity structure of the Cambay basin was studied using broadband and long-period magnetotelluric data along an eastwest profile of $\sim 200 \mathrm{~km}$ long profile. The twodimensional modeling showed a highly conductive $(\sim 1000 \mathrm{~S})$ thick Quaternary and Tertiary sediments within the Cambay rift zone. The Cambay rift zone is clearly delineated with a steeply dipping fault on the western margin, whereas the eastern margin of the rift zone gently dips along the NE-SW axis, representing a half-graben structure. A highly resistive body identified outside the rift zone is interpreted as an igneous granitic intrusive complex. Moderately conductive (30-100 Ohm.m) zones indicate underplating and the presence of partial melt due to plume-lithosphere interactions (Danda et al., 2017).

Utilizing the satellite magnetic data from CHAMP satellite mission, IIG in collaboration with NASA has generated a proxy-heat flow map of India which can provide relative information about the regional temperature distribution at depth and the concentration of subsurface geothermal energy (Rajaram et al., 2013).

\section{Mapping of Seismogenic Zones}

Ground Electrical and EM studies were carried out in the Koyna-Warna seismic zone to map the basalt cover and the electrical nature of the underlying granitic basement. These studies ruled out the presence of any sub-trappean sediments in this region and a welldefined crustal block structure, characterized by high resistive blocks interspersed with moderately conductive features, was identified. Also, conductive anomalies correlating with the known seismogenic structural features (e.g., the Konya Fault Zone, the 
west coast fault, the Donachiwada fault) filled with fluids, were mapped. It is inferred that, because of the NE to NS oriented compressive stress regime in the Indian shield due to the Himalayan collision tectonics, some of these structural features may become the locales of stress accumulation which may get released due to fluid filling of these zones under the influence of nearby reservoirs, resulting in triggering of seismicity (Patro et al., 2017).

For the region of 2001 Bhuj earthquake (Mw 7.6), Pavan Kumar et al. (2017) delineated the crustal geoelectric structure by MT and attributed the seismicity in this intraplate region to the fluid transfer from a reservoir at the Moho depth to the seismogenic zone through the South Wagad Fault and the north Wagad Fault that act as feeder channels for the fluid migration. In another MT study from the same region, Mohan et al. (2018) inferred the signatures of the Kachchh Mainland Fault (KMF) and the Katrol Hill Fault (KHF) in the geoelectric section. They also estimated the maximum sedimentary thickness of 2.3 $\mathrm{km}$ in this region.

The occurrence of lower crustal seismicity in the Central Indian Tectonic Zone (CITZ) of the Indian sub-continent was investigated using MT data and constraints from other geophysical studies. MT derived crustal resistivity models across the CITZ showed the presence of small volume $(<1 \mathrm{vol}$. \%) of aqueous fluids for the most part of lower crust and indicated brittle/semi-brittle lower crustal rheology in conjunction with xenoliths and other geophysical data. Additionally, MT results imaged localized deep crustal zones with higher fluid content (2.2-6.5 vol. \%) that leads to high pore pressure conditions. It is inferred that the fluid-rich pockets in the mid-lower crust seems to catalyze earthquake generation either as the source of local stress (fluid pressure), which together with the regional stress produce critical seismogenic stress conditions, or reduce the shear strength of the rocks to favor tectonic stress concentration at the low resistive (weak) zones, which is being transferred to seismogenic faults to cause earthquake (Abdul Azeez, 2016).

Interpretation of high resolution aeromagnetic data helped to delineate the horst and graben structures, several hitherto unknown dykes, faults, etc. over the seismically active Kutch Rift basin. Banni basin depicted aureole-like magnetic anomalies which may possibly relate to hydrocarbon induced micro seepages.

\section{Near-surface Imaging}

MT, AMT and Transient EM (TEM) techniques have been used to image the shallow subsurface structure for hydrocarbon, mineral and groundwater resources. An attempt was made to evaluate the efficacy of MT in the detection of sub-trappean sediments in basaltic trap covered areas of India using independent MT modeling as well as taking constraints from borehole and seismic data. Two different geological scenarios were considered, one trap covered area like the Saurashtra peninsula and the other where the trap itself is overlain by conductive sedimentary column represented by the Cambay basin. It was seen from inversion of synthetic as well as real data that in the first case MT alone produces highly dependable subsurface models, while in the second case a constrained inversion of MT data using inputs from seismic/borehole results for overlying Tertiary sediment thickness, provides a more realistic sub-basalt subsurface model than that retrievable from any one of the individual methodologies (Patro et al., 2015). Earlier, Manglik et al. (2009) developed an algorithm or joint inversion of MT, Direct Resistivity, and seismic reflection and refraction data and tested the efficacy of the technique for delineation of thin sedimentary layer sandwiched between the traps and the resistive basement.

AMT survey was carried out in the Bakreswar hot spring area of the eastern India to locate the geothermal source in the vicinity of the hot spring. The results show that the north-south fault close to Bakreswar is a shallow feature, not deeper than 300 $\mathrm{m}$, and thus cannot act as a heat source. The subsurface formation below the fault zone is highly resistive up to a great depth, indicating the absence of a heat source and geothermal reservoir in the vicinity of the Bakreswar hot spring.

In recent years, high-resolution heliborne TEM along with magnetics has been extensively used in India for uranium exploration and groundwater exploration programs. In uranium exploration, CSIRNGRI and Atomic Minerals Directorate for Exploration and Research (AMD) have used these techniques in association with radiometric parameter to cover different blocks in Jharkhand, Chhattisgarh, 
Andhra Pradesh, Rajasthan, Karnataka and Maharashtra states of India. Most of these studies are classified in nature but a few results have been published, e.g. by Sridhar et al. (2018) for the Kaladgi basin, Peninsular India where heliborne magnetic, electromagnetic and radiometric data were used to identify horst and graben structures and intra-basinal fault systems. CSIR-NGRI also took up heliborne surveys for groundwater exploration in six pilot areas of the country representing different hydro-geological conditions (Ahmed, 2014).

In another application of electrical and EM techniques, Manglik et al. $(2009,2011)$ employed MT and electrical resistivity tomography (ERT) to investigate the detailed deep and shallow electrical conductivity structure, respectively, of several potential High Voltage Direct Current (HVDC) sites in India. HVDC power transmission systems require setting up of specially designed ground electrodes at terminal ends of the transmission line to close the circuit with an earth return path. The design parameters of these electrodes need the information about the electrical conductivity structure within a radius and depth of several $\mathrm{km}$ of the site in order to ensure that the injected current penetrates deep enough into the earth.

\section{Concluding Remarks}

IAGA is one of the largest Associations of the IUGG that covers very diverse disciplines, from the magnetism of the Sun and other planetary bodies, solar winds, magnetosphere and upper Atmosphere, to the Earth's internal structure and processes. The techniques to observe the magnetic environments of the planetary bodies in general and the Earth in particular in space and time have also grown manifold and utilize ground based and multi-platform (airborne,

\section{References}

Abdelzaher M, Nishijima J, Saibi H, El-Qady G, Massoud U, Soliman M, Youni A and Ehara S (2012) A Coastal Aquifer Study Using Magnetotelluric and Gravity Methods in Abo Zenema, Egypt Pure Appl Geophys 169 1679-1692

Abdul Azeez K K (2016) Magnetotelluric constraints on the occurrence of lower crustal earthquakes in the intra-plate setting of Central Indian Tectonic Zone Acta Geologica Sinica (English Edition) 90 884-899

Abdul Azeez K K, Patro P K, Harinarayana T and Sarma S V S shipborne, satellites, balloons, etc.) sensors. The applications are also wide ranging, from the basic understanding of the magnetic field at present and in the past, to radio communication, geo-resource exploration, geo-environment, etc. An attempt is made here to provide a glimpse of the work done by Indian researchers in the last one decade in the field of Geomagnetism and Aeronomy. It is not an exhaustive review of all the work done during this period but a window to the topics covered within the framework of IAGA. The opportunities for future research in this field are enormous, e.g., Indian space missions for planetary exploration, launching of national geoscience missions for systematic probing of the Indian lithosphere at multi-scales, up-scaling of observatory network for detection of seismoelectromagnetic signals as precursors to earthquakes, development and application of magnetic and electromagnetic techniques for geo-resource exploration in complex geological settings and monitoring of the environment, etc.

\section{Acknowledgement}

Profs. Archana Bhattacharyya and B.R. Arora, and Drs. M. Ravi Kumar, Team-IIG, B.P.K. Patro, Kusumita Arora, and Gautam Rawat are gratefully acknowledged for providing valuable inputs for the article. I am thankful to Prof. Harsh K. Gupta, Chair, INSA-IUGG/IGU National Committee for inviting me to contribute this article for a P-INSA Special Volume and the Director, CSIR-NGRI, for permission to publish the article. I am thankful to the reviewers who provided valuable suggestions for the improvement of the manuscript. CSIR-NGRI contribution number NGRI/LIB/2018/Pub-42 under the project MLP640428(AM).

(2017) Magnetotelluric imaging across the Tectonic structures in the eastern segment of the Central Indian Tectonic Zone: Preserved imprints of polyphase tectonics and evidence for suture status of the Tan Shear Precam Res 298 325-340

Abdul Azeez K K, Veeraswamy K, Gupta A K, Babu N, Chandrapuri S and Harinarayana T (2015) The Electrical Resistivity Structure of Lithosphere across the Dharwar Craton Nucleus and Coorg Block of South Indian shield: Evidence of Collision and Modified and Preserved 
Lithosphere J Geophys Res (Solid Earth) 120 6698-6721

Ahmed S (2014). A new chapter in groundwater geophysics in India: 3D aquifer mapping through Heliborne Transient Electromagnetic Investigations J Geol Soc India 84 501503

Anil Kumar C P, Gopalsingh R, Selvaraj C, Nair K U, Jeyakumar H J, Vishnu R, Muralidas Sand Balan N (2013) Atmospheric electric parameters and micrometeorological processes during the solar eclipse on 15 January $2010 \mathrm{~J}$ Geophys Res118 5098-5104

Archana R K, Chandrasekhar N P, Arora K and Nagarajan N (2018) Constraints on scale lengths of equatorial electrojet and counter electrojet phenomena from the Indian sector $J$ Geophys Res: Space Physics 123 https://doi.org/10.1029/ 2018JA025213

Arora B R and Bhardwaj S K (2003) Spatial and frequency characteristics of equatorial enhancement of geomagnetic field variations J Atmo Solar Terr Phys 65 1283-1292

Arora B R and Veenadhari B (2015) Indian research highlights in the realms of IAGA during 2011-2014. In: Indian National Report for IUGG 2015 (Eds: Dimri V P) pp 28-60, INSA India

Arora B R, Rawat G, Naresh Kumar and Choubey V M (2012) Multi-Parameter Geophysical Observatory: gateway to integrated earthquake precursory research Current Science 103 1286-1299

Arora B R, Unsworth M J and Rawat G (2007) Deep resistivity structure of the northwest Indian Himalaya and its tectonic implications Geophys Res Lett 34 L04307 doi:10.1029/ 2006GL029165

Aujogue K, Pothérat A, Sreenivasan B and Debray F(2018) Experimental study of the convection in a rotating tangent cylinder J Fluid Mech 843 355-381

Basavaiah N (2012) Geomagnetism: Solid Earth and Upper Atmosphere Perspectives. Springer-Verlag

Basavaiah N and Khadkikar A S(2004) Environmental magnetism and it's application towards palaeomonsoon reconstruction $J$ Ind Geophys Union 8 1-14

Bhardwaj A, Pant T K, Choudhary R K, Nandy D and Manoharan P K (2016) Space Weather Research: Indian Perspective Space Weather 14 1082-1094

Bhatt S, Rana V and Mamtani M A (2017) Deciphering relative timing of fabric development in granitoids with similar absolute ages based on AMS study (Dharwar Carton, South India) J Struct Geol 94 32-46

Bhattacharyya A (2004) Role of E region conductivity in the development of equatorial ionospheric plasma bubbles
Geophys Res Lett 31 L06806 doi:10.1029/2003GL018960

Bhattacharyya A(2007) Geomagnetism and Aeronomy. In: Indian National Report for IUGG 2007 (Eds: Dimri V P) pp 2469, INSA India

Bhattacharyya A(2011) Indian contributions in the research areas of International Association of Geomagneitsm and Aeronomy (IAGA-IUGG) January 2007-December 2010. In: Indian National Report for IUGG 2011 (Gupta H K) pp 29-57, INSA India

Bhattacharyya A and Burke W J(2000) A transmission line analogy for the development of equatorial ionospheric bubbles J Geophys Res $\mathbf{1 0 5}$ 24, 941-24, 950

Bhattacharyya A, Basu S, Groves K M, Valladares C E and Sheehan R (2001) Dynamics of equatorial F region irregularities from spaced receiver scintillation observations Geophys Res Lett 28 119-122

Bhattacharyya A, Basu S, Groves K M, Valladares C E and Sheehan R (2002) Effect of magnetic activity on the dynamics of equatorial $\mathrm{F}$ region irregularities $J$ Geophys Res 1071489 doi:10.102 9/2002JA00964

Bhattacharyya A, Groves K M, Basu S, Kuenzler H, Valladares C E and Sheehan R (2003) L-band scintillation activity and space-time structure of low-latitude UHF scintillations Radio Sci 381004 doi:10.1029/2002RS002711

Bhattacharyya A, Kakad B, Sripathi S, Jeeva K and Nair K U (2014) Development of intermediate scale structure near the peak of the $\mathrm{F}$ region within an equatorial plasma bubble J Geophys Res (Space Physics) 119 3066-3076

Bhattacharyya A, Kakad B, Gurram P, Sripathi S and Sunda S (2017) Development of intermediate-scale structure at different altitudes within an equatorial plasma bubble: Implications for L-band scintillations J Geophys Res (Space Physics) 12 1015-1030

Breuer M, ManglikA, Wicht J, Truemper T, Harder H and Hansen $\mathrm{U}$ (2010) Thermo-chemically driven convection in a rotating spherical shell Geophy J Int 183 150-162

Campbell W H, Arora B R and Schiffmacher E R (1993) External Sq currents in the India Siberia region J Geophys Res 98 3741-3752

Chandrasekhar N P, Archana R K, Nagarajan N and Arora K (2017) Variability of equatorial counter electrojet signatures in the Indian region J Geophys Res: Space Physics 122 2185-2201 doi:10.1002/2016JA022904

Choudhary R K, St. Maurice J-P, Ambili K M, Sunda S and Pathan B M (2011) The impact of the January 15, 2010, annular solar eclipse on the equatorial and low latitude ionospheric densities J Geophys Res 116 A09309 doi: 10.1029/(2011)JA016504 
Danda N, Rao C K and Kumar A(2017) Geoelectric structure of northern Cambay rift basin from magnetotelluric data Earth Planet and Space 69 140, doi: 10.1186/s40623-017-07250

Dash J K, Pradhan S K, Bhutani R, Balakrishnan S, Chandrasekaran G and Basavaiah N (2013) Paleomagnetism of ca. $2.3 \mathrm{Ga}$ mafic dyke swarms in the northeastern Southern Granulite Terrain, India: Constraints on the position and extent of Dharwar craton in the Paleoproterozoic Precam Res 228 164-176

Doumouya V, Cohen Y, Arora B R and Yumoto K (2003) Local time and longitude dependence of the equatorial electrojet magnetic effects J Atmos Solar Terr Phys 65 1265-1282

Goswami S, Mamtani M A and Rana V (2018) Quartz CPO and kinematic analysis in deformed rocks devoid of visible stretching lineations: An integrated AMS and EBSD investigation J Struct Geol 115 270-283 https://doi.org/ 10.1016/j.jsg.2018.04.008

Gurubaran S, Shanmugam M, Jawahar K, Emperumal K, Mahavarkar P and Buduru S K(2017) A high-altitude balloon experiment to probe stratospheric electric fields from low latitudes Ann Geophys 35 189-201

Ismail-Zadeh A (2016) Geoscience international: the role of scientific unions Hist Geo Space Sci 7 103-123

Kakad B, Jeeva K, Nair K U and Bhattacharyya A(2007) Magnetic activity linked generation of nighttime equatorial spread $\mathrm{F}$ irregularities $J$ Geophy Res (Space Physics) 112 A07311doi:10.1029/2006JA012021

KakadB, Nayak C K and Bhattacharyya A (2012) Power spectral characteristics of ESF irregularities during magnetically quiet and disturbed days J Atmos Sol Terr Phys 81 41-49

Kakad B, Gurram P, Tripura Sundari P N B and Bhattacharyya A (2016) Structuring of intermediate scale equatorial spread F irregularities during intense geomagnetic storm of solar cycle 24 J Geophys Res (Space Physics) 121 7001-7012

Kakad B, Surve G, Tiwari P, Yadav V and Bhattacharyya A (2017) Disturbance dynamo effects over low latitude $F$ region: A study by network of VHF spaced receivers $J$ Geophys Res (Space Physics) 122 5670-5686

Kanu M O, Basavaiah N, Meludu O Cand Oniku A S(2017)Investigating the potential of using environmental magnetism techniques as pollution proxy in urban road deposited sediment Int J Environ Sci \& Tech 14 27452758

Lahiri S and Mamtani M A (2016) Scaling the 3-D Mohr circle and quantification of paleostress during fluid pressure fluctuation - Application to understand gold mineralization in quartz veins of Gadag (southern India) J Struct Geol $\mathbf{8 8}$
63-72

Lakhina G S(2003) Geomagnetism and Aeronomy. In: INSA National Report for IUGG 2003 (Eds: Gupta H K) pp 1858, INSA India

Lanza Rand Meloni A (2006) The Earth's magnetism. SpringerVerlag

Madhav Haridas M K, Manju G and Arunamani T(2016)Solar activity variations of nocturnal thermospheric meridional winds over Indian longitude sector J Atmosp Solar Terrest Phys 147 21-27

Mamtani M A (2014) Magnetic fabric as a vorticity gauge in syntectonically deformed granitic rocks Tectonophysics $\mathbf{6 2 9}$ 189-196

Mamtani M A and Arora B R (2005) Anisotropy of the magnetic susceptibility - A useful tool for the analyses of mutually deformed rocks Him Geol 26 175-186

Mamtani M A and Sengupta P (2010) Significance of AMS analysis in evaluating superposed folds in quartzites $\mathrm{Geol}$ Mag 147 910-918

Manglik A (2010) New insights into core-mantle boundary region and implications for Earth's internal processes Curr Sci 99 1733-1738

Manglik A, Adilakshmi L, Suresh M and Thiagarajan S (2015) Thick sedimentary sequence around Bahraich in the northern part of the central Ganga foreland basinTectonophysics $\mathbf{6 5 3} 33-40$

Manglik A, Verma S K and Kumar H(2009) Detection of subbasaltic sediments by a multi-parametric joint inversion approach J Earth Sys Sci 118 551-562

Manglik A, Verma S K, Sasmal R Pand Muralidharan D (2009) Application of Magnetotelluric Technique in selection of Earth Electrode Sites for HVDC Transmission Systems: An example from NE India e-Journal Earth Sci Ind 2 249257.

Manglik A, Wicht J W and Christensen U R (2010) A dynamo model with double diffusive convection for Mercury's core Earth Planet Sci Lett 289 619-628

Manglik A, Verma S K, Muralidharan D and Sasmal R P(2011) Electrical and electromagnetic investigations for HVDC ground electrode sites in India J Phy Chem Earth 36 14051411

Miglani R, Shahrukh M, Israil M, Gupta P K, Varshney S K and Sokolova E S (2014) Geoelectric structure estimated from magnetotelluric data from the Uttarakhand Himalaya, India J Earth Syst Sci 123 1907-1918

Mohan K, Chaudhary P, Patel P, Chaudhary B S and Chopra S(2018) Magnetotelluric study to characterize Kachchh 
Mainland Fault (KMF) and Katrol Hill Fault (KHF) in the western part of Kachchh region of Gujarat, India Tectonophysics 726 43-61

Mondal T K and Mamtani M A (2013) 3-D Mohr circle construction using vein orientation data from Gadag (southern India) - implications to recognize fluid pressure fluctuation $J$ Struct Geol $\mathbf{5 6}$ 45-56

Naganjaneyulu K and Santosh M (2012) The nature and thickness of lithosphere beneath the Archean Dharwar Craton, southern India: A magnetotelluric model J Asian Earth Sci 49 349-361

Pathak V, Patil S K and Shrivastava J P (2016) Tectonomagmatic setting of lava packages in the Mandla lobe of the eastern Deccan volcanic province, India: palaeomagnetism and magnetostratigraphic evidence Geol Soc London Spec Pub 445 https://doi.org/10.1144/SP445.3

Patro P K and SarmaS V S (2016) Evidence for an extensive intrusive component of the Deccan Large Igneous Province in the Narmada Son Lineament region, India from three dimensional magnetotelluric studies Earth Planet Sci Lett 451 168-176

Patro P K, Abdul Azeez K K, Veeraswamy K, Sarma S V S and Sen M K (2015) Sub-basalt sediment imaging - the efficacy of magnetotellurics J Appl Geophys 121 106-115

Patro P K, Borah U K, Babu G A, Veeraiah B and Sarma S V S (2017) Ground Electrical and Electromagnetic Studies in Koyna-Warna Region, India J Geol Soc Ind 90 711-719

Pavan Kumar G, Manglik A and Thiagarajan S (2014) Crustal geoelectric structure of the Sikkim Himalaya and adjoining Ganga Foreland Basin Tectonophysics 637 238-250

Pavan Kumar G, Mahesh P, Nagar M, Mahender E, Kumar V, Mohan K and Ravi Kumar M (2017) Role of deep crustal fluids in the genesis of intraplate earthquakes in the Kachchh region, northwestern India Geophys Res Lett 44 doi:10.1002/2017GL072936

Radhakrishna T, Krishnendu N R, Balasubramonian G(2013) Palaeoproterozoic Indian shield in the global continental assembly: Evidence from the palaeomagnetism of mafic dyke swarms Earth Sci Rev126 370-389

Rajaram M, Anand S P and Kumar H (2013) Proxy heat flux and magnetization model from satellite magnetic data J Geophys 34 55-61

Rastogi R G (1986) Evolution of geomagnetic studies in India Indian J Radio \& Space Phys 15 356-363

Rawat G(2014) Characteristic ULF band magnetic field variations at MPGO, Ghuttu for the 20 June 2011 earthquake in Garhwal Himalaya Curr Sci 106 88-93
Rawat G, Arora B R and Gupta P K (2014) Electrical resistivity cross section across the Garhwal Himalaya: proxy to fluid seismicity linkage Tectonophysics 637 68-79

Renjith A R, Mamtani M A and Urai J L (2016) Fabric analysis of quartzites with negative magnetic susceptibility - Does AMS provide information of SPO or CPO of quartz? $J$ Struct Geol 82 48-59

Sahoo S and Sreenivasan B (2017) On the effect of laterally varying boundary heat flux on rapidly rotating spherical shell convection Phys Fluids 29086602

Sangode S J (2014) Applications of magnetic stratigraphy into Quaternary records of India Gond Geol Mag 29 67-86

Shreedevi P R, Thampi S V, Chakrabarty D, Choudhary R K, Pant T K, Bhardwaj A and Mukherjee S (2016) On the latitudinal changes in ionospheric electrodynamics and composition based on observations over the $76-77^{\circ} \mathrm{E}$ meridian from both hemispheres during a geomagnetic storm J Geophys Res (Space Physics) 121 1557-1568

Sridhar M S, Yalla H, Maurya A K and Chaturvedi A K (2018) Modelling of high-resolution aeromagnetic data to decipher structural deformation in parts of Kaladgi basin, Peninsular India Near Surface Geophysics 16 1-12 doi: 10.3997/ 1873-0604.2017047

Sripathi S, Bose S, Patra A K, Pant T K, Kakad B and Bhattacharyya A(2008) Simultaneous observations of ESF irregularities over Indian region using radar and GPS Ann Geophys 26 3197-3213

Srivastava R K, Kumar S, Sinha A K and Chalapathi Rao N V (2014) Petrology and geochemistry of high-titanium and low-titanium mafic dykes from the Damodar valley, Chhotanagpur Gneissic Terrain, eastern India and their relation to mantle plume(s) J Asian Earth Sci 84 35-50

Thampi S V, Shreedevi P R, Choudhary R K, Pant T K, Chakrabarty D, Sunda S, Mukherjee S and Bhardwaj A(2016) Direct observational evidence for disturbance dynamo on the day-time low-latitude ionosphere: A case study based on the 28 June 2013 space weather event $J$ Geophys Res (Space Physics) 121 10,064-10,074

Valet J-P, Besse J, Kumar A, Vadakke-Chanat S and Philippe E (2014) The intensity of the geomagnetic field from $2.4 \mathrm{Ga}$ old Indian dykes Geochem Geophys Geosyst 15 24262437

Venkateshwaulu M and Chalapathi Rao N V(2013) New palaeomagnetic and rock magnetic results on Mesoproterozoic kimberlites from the Eastern Dharwar craton, southern India: Towards constraining India's position in Rodinia Precam Res 224 588-596 
Venkateshwarlu $M$ and Mallikarjuna Rao J(2013) Paleomagnetism of Bhander Sediments from Bhopal Inlier, Vindhyan Supergroup J Geol Soc Ind 81 330-336

Vichare G and Rajaram R (2011) Global features of quiet time counter electrojet observed by Oersted J Geophys Res 116 A04306 doi: 10.1029/2009JA015244

Vichare G, Rawat R, Hanchinal A, Sinha AK, Dhar A and Pathan B M (2012) Seasonal evolution of Sq current system at sub-auroral latitude Earth Planets and Space $641023-$ 1031

Vineeth C, Mridula N, Muralikrishna P, Pant T K and Kumar K K (2016) First Observational Evidence for the Connection between the Meteoric Activity and Occurrence of Equatorial Counter Electrojet J Atmosp Solar Terrestrial Phys 147 71-75
Warrier A K, Mahesh B S, Rahul Mohan, Shankar R, Asthana R and Ravindra R (2014) Glacial-interglacial climatic variations at the Schirmacher Oasis, East Antarctica: The first report from environmental magnetism Palaeogeography, Palaeoclimatology, Palaeoecology 412 249-260

Yadav S, Sridharan R, Sunda S and Pant T K (2017) Further refinements to the Spatio temporal forecast model for Lband scintillation based on comparison with $\mathrm{C} / \mathrm{NOFS}$ observations: Forecast model for L-band scintillation $J$ Geophys Res (Space Physics) 122 5643-5652. 